\title{
REVENUE AND EFFICIENCY \\ IN MULTI-UNIT UNIFORM-PRICE AUCTIONS
}

\section{Michal Břeský}
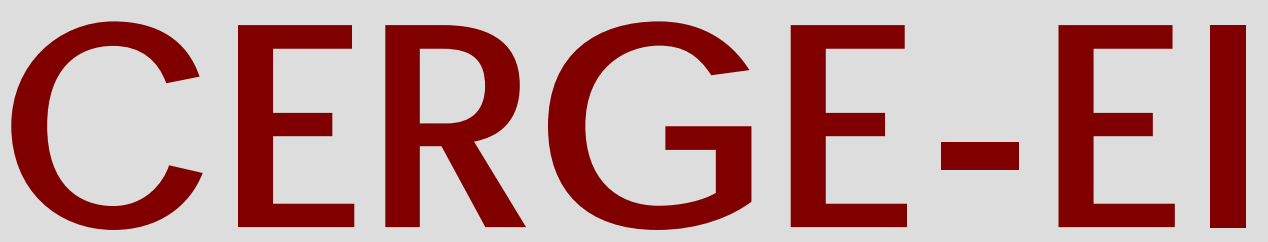

Charles University CenterforEconomic Research and Graduate Education Academy of Sciences of the Czech Republic Ec onomic s Institute 


\title{
Working Paper Series $\quad 384$ (ISSN 1211-3298)
}

\section{Revenue and Efficiency in Multi-Unit Uniform-Price Auctions}

\author{
Michal Břeský
}

CERGE-EI

Prague, May 2009 
ISBN 978-80-7343-185-3 (Univerzita Karlova. Centrum pro ekonomický výzkum a doktorské studium)

ISBN 978-80-7344-174-6 (Národohospodářský ústav AV ČR, v.v.i.) 


\title{
Revenue and Efficiency in Multi-Unit Uniform-Price Auctions
}

\author{
Michal Břreský* \\ CERGE-EI ${ }^{\dagger}$
}

\begin{abstract}
I show that in a private value multi-unit uniform-price auction, the reservation price increases both the efficiency and revenue. In equilibrium the difference between the true value of a unit and the submitted bid (shading) is different for each unit; therefore, the seller cannot allocate units efficiently, i.e., to those who value them the most. When the seller increases the reservation price, the bidders increase their bids on the units with greater shading. Then more often the units are allocated among those who have higher values for them, that is, efficient, although some bidders with a low value do not participate in the auction. In contrast to some other auction formats, for a low range of reservation prices, the higher the reservation price, the higher is both the expected efficiency and revenue.
\end{abstract}

\begin{abstract}
Abstrakt
Studie ukuzuje, že zvýšení minimální přijímané ceny pro účastníky více-objektové aukce $\mathrm{s}$ jednotnou cenou zvýší jak očekávaný výnos $\mathrm{z}$ aukce, tak efektivitu alokace prodávaných jednotek. Když účastníci používají rovnovážné strategie, tak v této aukci podávají objednávky, které jsou nižší než má je hodnota jednotky pro účastníka aukce. Navíc, protože je toto snížení různé pro jednotlivé jednotky, prodávající nemůže prodávané jednotky prodat efektivně - těm, pro něž je hodnota jednotek nejvyšší. Když prodávající zvýší minimální pijímanou cenu, účastníci aukce zvýší objednávky na jednotky, kde je snížení objednávky oproti honotě jednotky nejvyšší. Potom se prodávané jednotky častěji prodají těm účastníkům, kteří mají pro jednotky vyšší hodnotu, což je efektivnější, ačkoliv někteří účastníci s nízkou hodnotou pro jednotky se nezúčastní aukce. Oproti některým jiným aukčním prodejním způsobům, pokud je minimální přijímaná ceny v intervalu malých hodnot, tak $\mathrm{v}$ této aukci s jednotnou cenou platí, že čím vyšší je minimální přijímaná cena, tím vyšší je jak očekávaný výnos, tak efektivita alokace jednotek.
\end{abstract}

JEL Classification: D44

Keywords: multi-unit auction, multiple-object auction, market efficiency, optimal selling mechanism, discriminatory and uniform price auction with reservation price.

*I would like to thank Philip Reny, Avner Shaked, Viatcheslav Vinogradov, Michal Kejak, Levent Celik, Andreas Ortmann, and Jan Hanousek for their helpful comments.

I would appreciate any comments that you can sent to michal.bresky@cerge-ei.cz. Future extensions of this paper can be found at home.cerge-ei.czlbresky.

${ }^{\dagger}$ CERGE-EI is a joint workplace of the Center for Economic Research and Graduate Education, Charles University, and the Economics Institute of Academy of Sciences of the Czech Republic.

Address: CERGE-EI, P.O. Box 882, Politických vězňů 7, Prague 1, 111 21, Czech Republic 


\section{INTRODUCTION}

An auction is an exchange mechanism with asymmetric information. It can be treated as a game in which the seller offers one or more units (of the same type) to the participants. The seller does not know the bidder's value of any particular unit, but he can set up an explicit set of institutional rules determining resource allocation and prices on the basis of bids from the auction participants. In Vickrey auctions (Vickrey (1961)) bidders reveal the true valuation of each unit and the final allocation is efficient. Krishna (2002) formulates conditions when the equilibrium in a multi-unit auction is efficient. However, the equilibrium strategies in a multi-unit uniform-price auction do not satisfy this condition (see Morgan (2001)).

This paper analyzes efficiency in a multi-unit auction with a positive reservation price. The effect of reservation prices on a multi-unit auction is difficult to assess in general (see Zheng (2008)). I demonstrate that the reservation price is an important policy tool that may increase efficiency (or welfare) in multi-unit uniform-price auctions. I show that the higher the reservation price is, the higher is the seller's revenue and the higher is the efficiency of a final allocation of units that could be attained in a multi-unit uniform-price auction. The only main important prerequisite of this result is that the reservation price increases the bidder's equilibrium strategy in a specific way that is inherent to the uniform-price auction. Thus the reservation price effect on efficiency is in contrast to other auction formats; e.g., the reservation price decreases efficiency in the Vickrey auction and single-unit auctions with symmetric bidders. Therefore it can be added to the list of results from mechanism design and auction theory that fail to extend the single-unit/single-dimensional context to the multi-unit/multi-dimensional one, e.g., Armstrong (1996), Perry and Reny (1999), and Levin (2004).

For a benchmark of an auction game I follow the model with symmetric 
risk-neutral bidders who have independent-private values when the payment is a function of bids alone as suggested by McAfee and McMillan (1987). The only additional assumptions are that the seller offers more than one unit for sale and the bidders demand two units that I call "initial" and "subsequent." This model has been analyzed in Engelbrecht-Wiggans and Kahn (1998a). They show basic features of equilibrium strategies. I focus on the difference between the bidder's true value and the submitted bid which is called "shading" or "demand reduction" in the literature. In a uniform-price auction with no reservation price, a different shading in strategies on initial and subsequent units is present and prevents the seller from reaching a Pareto-efficient distribution of units. I show that when the seller sets some specific (optimal) reservation price, the difference in shading on the initial and subsequent unit decreases, which can prevent some inefficient allocations of units, and, moreover, the seller gains higher revenue.

For illustration, imagine two bidders in an auction with 2 units for sale with zero reservation price. Each bidder has two values $v_{1}, v_{2}$ and $v_{1}^{\prime}, v_{2}^{\prime}$ and submits $b_{1}, b_{2}$ and $b_{1}^{\prime}, b_{2}^{\prime}$ for the two units the seller offers. If the values are such that $v_{1}^{\prime}>v_{2}^{\prime}>v_{1}>v_{2}$, then it is efficient if the first bidder wins both units. But in many cases equilibrium strategic behavior forces the bidders to submit bids with the ordering $b_{1}^{\prime}>b_{1}>b_{2}^{\prime}>b_{2}$. If the seller increases the reservation price above $v_{1}$, the second bidder does not submit a bid above the reservation price, and the first bidder wins both units, which is an efficient outcome. ${ }^{1}$ At the same time revenue typically increases. This reasoning is valid for the multi-unit uniform-price and to some extent for other multi-unit auctions if $b_{1}>b_{2}^{\prime}$ when $v_{1}<v_{2}^{\prime}$. On the other hand, setting the reservation price too high introduces inefficiency when the supply is greater than the number of submitted bids (e.g.,

\footnotetext{
${ }^{1}$ Throughout the text, the words "above" and "below" mean strictly above and strictly below.
} 
$\left.v_{1}^{\prime}>R>v_{2}^{\prime}>v_{1}>v_{2}\right)$. In summary, the seller faces a trade off between these two sources of inefficiency and the total effect is ambiguous. In this paper I show that the expected efficiency typically increases when the seller increases the reservation price above 0 in the uniform-price auction.

I develop a model for a uniform-price auction when each bidder submits two bids, but it is intuitive that a similar effect is present when each bidder submits more bids. Moreover, a similar trade off is likely to be present in other auction formats (e.g., pay-your-bid) when the higher reservation price decreases shading difference across initial and subsequent units. These two properties are present in the model of this paper, but it is a question of future research to check these two properties formally for other multi-unit auctions.

In addition, the results of this paper also contribute to the literature on efficient multi-unit auction design. Krishna (2002, Proposition 13.3.) argues that equilibrium strategies cannot be efficient if a shading difference across units is present. The seller who uses submitted bid ordering to allocate units cannot attain efficient allocations when bidders use different shading across initial and subsequent units. This paper, additionally, confirms that any means that decreases shading differences can improve efficiency of the final allocation. The reservation price is an example of such a mean in a multi-unit uniformprice auction when the number of bidders is small.

The paper is organized as follows. At first I discuss the relationship of this paper to other studies. Then, in the next section, I develop a model of a uniform-price auction for $n$ bidders, $k$ units of supply, and a reservation price $R$. I also derive expressions for the expected efficiency measures. In the rest of the paper, I disentangle two sources of inefficiency, show the general conditions when the optimal reservation price that maximizes efficiency is positive, and demonstrate this main contribution of the paper with a simple example. Finally, I conclude the paper. 


\section{RELATION TO THE LITERATURE}

Even in early studies (e.g. Back and Zender (1993)) the authors argued that standard features of single-unit auctions cannot be easily extended to multi-unit environments. To design an efficient multi-unit auction is a difficult task, in general (see Zheng (2008) for a recent survey). In a common-value context, Dasgupta and Maskin (2000), Perry and Reny (2002) and Perry and Reny (2005) show how to a design an efficient auctions when values are interrelated, but only in a limited case when each bidder receives a single-dimensional signal only. Jehiel and Moldovanu (2001) and Dasgupta and Maskin (2000) show that efficiency is not attainable when values are interrelated and each bidder's information signal is multi-dimensional. For another detailed survey see Klemperer (2000).

In a private-value multi-unit auction context, Ausubel and Cramton (1996) emphasize that a uniform-price sealed-bid auction is not efficient unless the bidder's value of each unit is the same. The Vickrey sealed bid-auction (Vickrey (1961) and its dynamic counterpart (see Ausubel (2004)) are efficient. Finally, Krishna (2002, Proposition 13.3.) argues that in any private-value multi-unit auction “... equilibrium can be efficient if and only if bidding strategies are separable and symmetric across both bidders and objects." 2 Therefore it seems that the Vickrey multi-unit auction is the only sealed bid multi-unit efficient auction in this context, but it is not often used in real life for various reasons that were discussed in Morgan (2001). He also provides examples to compare essential intuitive differences between multi-unit Vickrey and uniform-price auctions both in private-value and common-value contexts. Some of the papers mentioned above show that the uniform-price auction with multi-dimensional

\footnotetext{
${ }^{2}$ Krishna (2002) uses the term "symmetry in strategies across objects" to mean "absence of the diference in shading across units" in my terminolgy. But I use the term symmetric strategies to mean the "symmetry in strategies across bidders only" excluding "symmetry in strategies across objects" to simplify the terminology of this paper.
} 
signals is not efficient even in a simple private value context.

From this point of view, this paper takes a completely different route to analyze the optimal multi-unit auction design that is not as general but goes further beyond the results of the existing literature including all the papers mentioned above. The essential message of this paper is the suggestion that a positive reservation price increases the seller's revenue and increases the efficiency when the signals are multi-dimensional. It shows not only that one cannot design a uniform-price multi-unit auction efficiently, but it also clearly explains where is the efficiency lost and how to improve the efficiency, although zero efficiency loss is not fully attained. Moreover, numerous studies including Ausubel and Cramton (1996), Engelbrecht-Wiggans and Kahn (1998a), Krishna (2002), Menezes and Monteiro (2005) and Zheng (2008) discuss the so-called demand reduction effect or shading present in a multi-unit uniformprice auction. This effect claims that the seller may often collect zero revenue when bidders use equilibrium strategies in the uniform-price auction, and it is considered to be the main drawback of this auction. The demand reduction effect is also present in Engelbrecht-Wiggans and Kahn (1998a), who derive essential features of equilibrium strategies that I use as a benchmark model. It is not difficult to argue that setting a positive reservation price is an important policy tool that operates against the "demand reduction" effect; i.e., the higher the reservation price is, the higher the seller's revenue is (see e.g., Back and Zender (1993)). An important contribution of this paper is that increasing the reservation price above zero not only diminishes the demand reduction and increases the seller's revenue but, in addition, also improves efficiency, which has not been pointed out in the literature yet.

Jehiel and Moldovanu (2001a) use a simplified model of the private-value uniform-price auction with only two bidders to argue that the seller, who sells the units in bundles, collects more revenue than in an efficient auction. 
They, therefore, conjecture that bundling cannot be efficient because the seller collects too much revenue. In my paper no bundling occurs, and one can informally conjecture that in a multi-unit private-value uniform-price auction the seller who sets a zero reservation price collects not enough revenue to be efficient. Therefore, after increasing the reservation price the seller collects more revenue and efficiency improves.

The effect of the reservation price on efficiency is less and less significant as the number of bidders is larger and larger. It is intuitive if one realizes that the reservation price can be treated as an additional submitted bid by the seller (see Jackson and Swinkels (2005)). Moreover, it is in accordance with the result by Swinkels (2001, section 5.2 and 5.3) who shows that the uniformprice auction is asymptotically efficient as the number of bidders approaches infinity. The same reasoning is valid for the model of this paper. Therefore, the inefficiency improvement caused by the change in the reservation price change decreases as the number of bidders approaches infinity.

Unfortunately, the result of this paper cannot be proved for any distribution of values (see the discussion of conditions in section 4 and Appendix). On the other hand, the effect of the positive reservation price on efficiency is present whenever the "demand reduction" called "pooling of bids at zero" in Engelbrecht-Wiggans and Kahn (1998a) is present in the auction and at the same time the reservation price increases the subsequent strategy for a given subsequent value. To ensure that the increase of the reservation price increases the bidder's subsequent strategy is intuitive and sufficient conditions on the distribution of bidder's values are provided. 


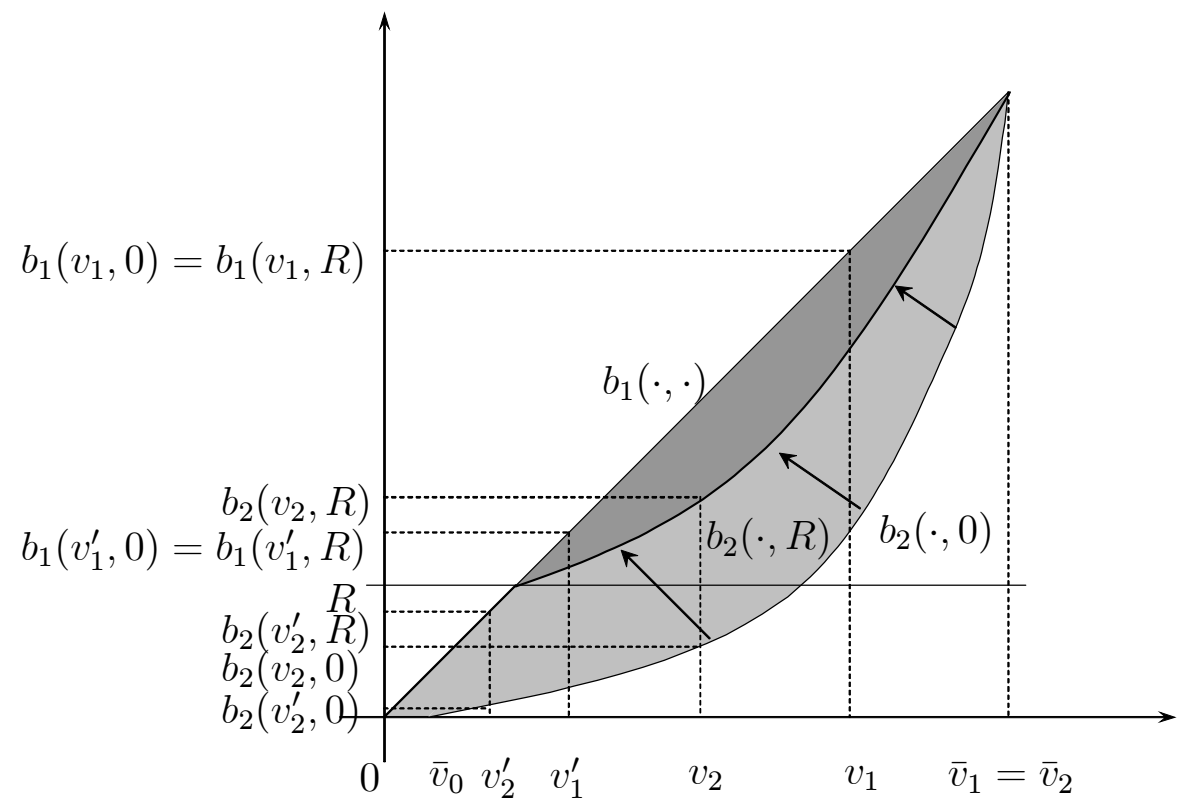

Figure 1: The effect of reservation price on bidding strategies. Dark shaded area represents the integration range in MLoss formula below when the reservation price is positive.

In symmetric single-unit private value auctions, a revenue maximizing seller sets the reservation price above the seller's value, but it has negative effect on efficiency (McAfee and McMillan (1987)). It is also supported by Menezes and Monteiro (2005) and Krishna (2002)). In a multi-unit auction context the later two studies, in addition, show that a uniform-price auction format gives a bidder the incentive to reduce his subsequent bid in order to pay less for the initial unit. This introduces inefficiency and revenue loses when the seller sets the reservation price to zero because the bidders bid the true value on the initial unit.

Therefore the seller who sets a positive reservation price offsets this ineffi- 
ciency that is inherent in the uniform-price auction. The positive reservation price has a significant effect on the efficiency of multi-unit auctions. The effect of the reservation price on efficiency is not the same for all multi-unit auction formats. When the equilibrium difference in strategic shading on the initial and subsequent units is not significant (e.g., in a Vickrey auction there is no difference in shading), then any positive reservation price decreases efficiency.

Similarly to Jehiel and Moldovanu (2001a) I split sources of inefficiency between the misallocation effect and supply restriction effect that I denote as MLoss and ULoss, respectively, in Section 4. If the seller sets a positive reservation price, then shading diminishes because each bidder strictly increases his subsequent bid (see Figure 1) for any given subsequent value. Therefore, the difference in shading across the initial and subsequent unit decreases (cf. the dark area and the same area with the light shaded area added). Figure 1 illustrates that the smaller the shaded area is, the smaller is the misallocation inefficiency that I call MLoss. Note that if the shaded area fully disappears, then the MLoss is zero and the necessary conditions for efficient multi-unit auction provided by Krishna (2002) are valid. In other words, one can consider the shaded area as a kind of measure closely related to misallocation inefficiency. This source of inefficiency is diminished by the reservation price. On the other hand, the positive reservation price increases the ULoss because the bidders bid below the reservation price for their low values. In short, an essential prerequisite for the effect studied in this paper is that each bidder bids fairly below his value for some but not all units (Morgan (2005, p. 815)). A question for future research is to what extent the same occurs for other auction formats and under what conditions. Moreover, in some cases, the seller can improve efficiency even more when setting different reservation prices for initial and subsequent units (a reservation price schedule) or relaxing the number of submitted bids that each bidder can submits. 
In single-unit auctions, the reservation price decreases efficiency (McAfee and McMillan (1987)). Swinkels (1999, pp. 509-510) noticed that multi-unit demands introduce difference in shading across units which he calls endogenous asymmetry. Comparisons of the uniform-price and pay-your-bid auctions are difficult (cf. Katzman (1999)). Ausubel and Cramton (1996) show that the efficiency ranking of pay-your-bid and the uniform-price is ambiguous. Lebrun and Trimblay (2003) show that bidders submit a more aggressive bid on the subsequent unit in the pay-your-bid auction. The shape of the equilibrium strategy in uniform-price and pay-your-bid auctions (see EngelbrechtWiggans and Kahn (1998a), McAdams (2006) and Engelbrecht-Wiggans and Kahn (1998b)) suggests that the difference in shading on each unit is greater in the uniform-price auction format. Therefore it seems that the uniformprice auction outcome is more sensitive to the proper reservation price setting than the pay-your-bid auction. The reason for this is that in the pay-your-bid auction the subsequent bid influences the price of all previous units in the uniform-price auction and, therefore, the bidders have an incentive to shade their values more than in the pay-your-bid auction. This intuition is supported by the case when the reservation price is 0 because in the uniform-price auction the bidders bid 0 for the low range of values but not in the pay-your-bid auction (see Engelbrecht-Wiggans and Kahn (1998b)). The proper reservation price setting requires more information gathering and strategic considerations from the seller to design the auction.

\section{THE MODEL OF THE UNIFORM-PRICE SEALED BID AUCTION}

I describe a model of multi-unit auctions with risk-neutral bidders having continuous distributions of private values similarly as in Engelbrecht-Wiggans 
and Kahn (1998a), and Noussair (1995). ${ }^{3}$ Let us consider a seller who plans to sell $k(k \geq 2)$ identical units to $n(n \geq 1)$ bidders each of whom submits two bids. I assume that bidders are symmetric and omit the bidder's index $i$ unless needed for clarity. Each bidder observes private information $v=\left[v_{1}, v_{2}\right]$ which is the initial and subsequent value of the unit the bidder can win. Moreover, the subsequent value is less than or equal to the initial value for each bidder, i.e., $v_{1} \geq v_{2} \cdot{ }^{4}$

Let $G\left(v_{1}, v_{2}\right)$, which has support on interval $\mathcal{V}=\left[0, \bar{v}_{1}\right] \times\left[0, \bar{v}_{2}\right]$, denote the probability distribution function of the private values $v_{1}$ and $v_{2}$ where $\bar{v}_{1}$ and $\bar{v}_{2}$ are the upper boundaries of the support..$^{5}$ I denote the marginal distribution of initial and subsequent units as $G_{1}\left(v_{1}\right)$ and $G_{2}\left(v_{2}\right)$, and their densities as $g_{1}\left(v_{1}\right)$ and $g_{2}\left(v_{2}\right)$.

The Game. Before the auction the seller announces the number of units for sale and a reservation price $R \in[0, \infty)$. Each bidder submits two sealed finite bids $b_{1}, b_{2} \in[0, \infty)$, that are denoted as $b$. If more than $k$ bids are submitted above the reservation price $R$, then the seller chooses the $k$ highest bids that win a unit in the auction. A tie occurs when the $k$ th and $k+1$ st highest bids are equal and the seller breaks such a tie randomly. ${ }^{6,7}$ The auction price that each bidder pays for winning each unit is equal to $k+1$ st highest bid. If less than $k+1$ bids are submitted above or equal to the reservation price $R$, then each of them wins a unit and pays the price $R$.

\footnotetext{
${ }^{3}$ A similar model was used by Noussair (1995), and Engelbrecht-Wiggans and Kahn (1998a).

${ }^{4}$ If not, assume that the bidder orders the values for units without loss of generality.

${ }^{5}$ Symbol $\times$ means the Cartesian product. Note that $\bar{v}_{1} \geq \bar{v}_{2}$.

${ }^{6} \mathrm{~A}$ specific rule for breaking ties is not important. It is known that with "reasonable" tie-breaking rules no ties occur in equilibrium. See Jackson and Swinkels (2005) and Bresky (2008a) for details.

${ }^{7}$ The definition of the tie allows other bids to be tied with the $k$ th and $k+1$ st highest bids.
} 
A bidder's ex post payoff depends on the number of units he wins, $J$, the realization of his values, $v$, his bids, $b$, his opponent's bids, $b_{-}$, and the reservation price, $R$,

$$
\pi\left(v, b, b_{-}, R\right)=\sum_{j=1}^{J}\left(v_{j}-p\left(b, b_{-}, R\right)\right),
$$

where $p\left(b, b_{-}, R\right)$ is the uniform auction price paid for winning each unit.

Since the seller orders bids after submission, I assume without loss of generality that each bidder submits ordered bids $b_{1} \geq b_{2}$. I denote the set of all these bid pairs as $\mathcal{B}$. A pure strategy is a list of submitted bids based on the observed information that bidder $i$ knows before the auction, including his private values, the reservation price, the distribution of all bidder values, the number of units for sale, and the number of opponents. For the sake of simplicity I will write the pure strategy as a function of private values only. Then the pure strategy is a mapping $b(\cdot): \mathcal{V} \rightarrow \mathcal{B}\left(b(v)=\left[b_{1}(v), b_{2}(v)\right]\right)$ such that $b_{1}(\cdot)$, and $b_{2}(\cdot)$ are measurable.

When opponents use strategies $b_{-}(\cdot)$, then the ex ante pointwise payoff to the bidder, whose values are $v$ and who bids $b$, is

$$
\pi\left(v, b \mid b_{-}(\cdot)\right)=E\left(\pi\left(v, b, b_{-}, R\right)\right)
$$

The expectations are taken over opponent values $v_{-}$. The probability measure of $\pi\left(v, b, b_{-}, R\right)$ is induced by the opponent strategies $b_{-}(\cdot)$ and the random tie-breaking rule if a tie occurs with positive probability. The detailed formula is in Bresky (2008b), or Engelbrecht-Wiggans and Kahn (1998a). I use the word payoff to mean the ex ante payoff when no confusion arises.

The bidder maximizes his payoff from a strategy $b(\cdot)$

$$
\max _{b(\cdot)} E\left(\pi\left(v, b \mid b_{-}(\cdot)\right)\right),
$$

where the expectations are taken over $v$ which induces the probability measure of $\pi\left(v, b \mid b_{-}(\cdot)\right)$. 
Engelbrecht-Wiggans and Kahn (1998a) use and discuss mild conditions on the distribution of values to guarantee the equilibrium strategies are "wellbehaved" (cf. Menezes and Monteiro (2005), Theorem 24)). To simplify the analysis I will focus our attention on the perfect equilibria only. They were defined and analyzed in Engelbrecht-Wiggans and Kahn (1998a)., ${ }^{8,9}$ Throughout the rest of the paper I take the liberty to use the result shown in EngelbrechtWiggans and Kahn (1998a, section 3) on the shape of symmetric equilibrium strategies. The strategies are depicted in Figure 1. For $k=3, \cdots, 2 \cdot n-1$, I will assume that in symmetric equilibrium a bidder reveals his initial value in the initial bid and the subsequent bid is an increasing function in reservation price $R$ and value $v_{2}$ and up to the range of values from $\left[R, \bar{v}_{0}\right)$ when the number of bidders is at least as high as the number of units.

$$
\begin{aligned}
& b_{1}\left(v_{1}, v_{2}, R\right)=v_{1} \text { for } v_{1} \in\left[0, \bar{v}_{1}\right], \text { and } \\
& b_{2}\left(v_{1}, v_{2}, R\right)=\left\{\begin{array}{cl}
v_{2} & \text { for } v_{2} \in[0, R) \\
R & \text { for } v_{2} \in\left[R, \bar{v}_{0}\right) \\
b_{2}\left(v_{2}, R\right) & \text { for } v_{2} \in\left[\bar{v}_{0}, \bar{v}_{2}\right]
\end{array} \text { for some } \bar{v}_{0} \in\left[R, \bar{v}_{2}\right](3.4)\right.
\end{aligned}
$$

where $b_{2}\left(v_{2}, R\right)$ is increasing in $v_{2}$ and $R$ and

$$
\bar{v}_{0}=0 \text { if } R>0 \text { or } 2 n-1 \geq k \text {. }
$$

The conditions A and B in the appendix derived in Engelbrecht-Wiggans

\footnotetext{
${ }^{8}$ For $n=k \geq 2$ and $R=0$ consider the following equilibrium without perfection $b_{1}\left(v_{1}, v_{2}, R\right)=\bar{v}_{1}$ and $b_{2}\left(v_{1}, v_{2}, R\right)=0$ (see explanation in Swinkels, Jeroen $(2001,5.1$ ) and Blume, Heidhues, Lafky, Münster, and Zhang (2009)). When taking this equilibrium into account Theorem 4 below is valid with a stronger effect, but the notation and proofs of Theorem 3 and 4 are more complicated.

${ }^{9}$ McAdams (2006) shows that every equilibrium strategy (pure or mixed) are equivalent with pure weakly increasing ones in terms of the bidder's and seller's payoff, allocation of units and distribution of bids. This result provides a justifiction for focusing on pure equilibria.
} 
and Kahn (1998a) are sufficient to guarantee that the equilibrium strategies have the form (3.4). One can easily check that the features of equilibrium strategies remain the same even when the seller sets a positive reservation price $R .^{10}$ The intuition is that the reservation price can be considered as additional bids of an additional bidder that does not affect qualitatively the essential features of the strategies.

For illustration I will just argue that $\bar{v}_{0}=0$ when $R>0$. By the way of contradiction, assume that $\bar{v}_{0} \in\left(0, \bar{v}_{2}\right)$ and $R>0$ and all bidders follow the strategy (3.4). Consider the two bidders with subsequent value from $\left[R, \bar{v}_{0}\right)$ who bids $R$ and assume that exactly $k-3$ opponent bids of the other $n-2$ opponent bidders are above $R$, which obviously occurs with positive probability by condition $\mathrm{A}$ and the fact that bidders bid at or below their values in perfect equilibrium. Then these $k-3$ opponent bids are winning units, and the two bidders initial bids are also winning a unit. Hence, the two subsequent bids of the two bidders who bids $R$ compete for one remaining unit. Therefore if one of the two bidders increases his subsequent bid to $R+\varepsilon$, then he wins surely in this situation, his payoff increases by a jump. Such a change in subsequent bid can increase the price the bidder pays for his initial unit when his subsequent bid is the first rejected bid. But the price increase can be made arbitrarily small if $\varepsilon$ is sufficiently close to 0 . Therefore such a bidder is better off when bidding $R+\varepsilon$ insead of $R$ which is a contradiction with equilibrium best response. One can check that the arguments follow the same steps as in Engelbrecht-Wiggans and Kahn (1998a, proof of Theorem 3.1).

The condition $\mathrm{B}$ is sufficient for $\bar{v}_{0}>0$ when $R=0$ and $k \geq 3$. The condition $\mathrm{C}$ in the appendix is my additional assumption sufficient for the symmetric equilibrium strategies $b_{2}\left(v_{2}, \cdot\right)$ to be increasing in $R$ and continuous in $v_{2}$ for values $v_{2}$ above $R$. Then the multi-unit auction poses equilibria for

\footnotetext{
${ }^{10}$ See Bresky (2008b) for details if necessary.
} 
which the final Theorem 4 is applicable. All the conditions A, B and C are sufficient but not necessary in general, and I discuss them later.

For $k=2$ the shape of equilibrium strategies can be more rich and I will not analyze this case in general. In Example 2 below I show that the main idea works even in this case when the distribution of values is uniform and the demand reduction is present and the reservation price diminishes the demand reduction. Now let me illustrate the equilibrium strategies of this game when $k=2$.

Example 1. Suppose two units are auctioned, both of the two bidders' initial and subsequent values $\left(v_{1}, v_{2}\right)$ are uniformly distributed on $\left\{v \mid \bar{v} \geq v_{1} \geq v_{2} \geq 0\right\}$ where $\bar{v}=\bar{v}_{1}=\bar{v}_{2}$ is the upper boundary of the value support. ${ }^{11}$ Then it can be verified that the following is a symmetric Nash equilibrium strategy ${ }^{12}$

$$
b_{1}\left(v_{1}, v_{2}, R\right)=v_{1} \text { and } b_{2}\left(v_{1}, v_{2}, R\right)=\left\{\begin{array}{c}
R \text { if } v_{2}>R \\
0 \text { if } v_{2} \leq R
\end{array} .\right.
$$

I will assume that the seller does not assign any value for the units. The seller can maximize revenue, efficiency, or a mixture of both. Let me denote $K$ as the number of bids greater than or equal to $R$. Then the seller's revenue $R e v$ is

$$
\operatorname{Rev}(R)=\left\{\begin{array}{cc}
k \cdot c & \text { if } k<K \\
K \cdot R & \text { if } k \geq K
\end{array},\right.
$$

where $c$ is the $k+1$ st highest submitted bid.

\footnotetext{
${ }^{11}$ The density function is $g\left(v_{1}, v_{2}\right)=\frac{2}{\bar{v}^{2}}$ if $\bar{v} \geq v_{1} \geq v_{2} \geq 0$ and otherwise $g\left(v_{1}, v_{2}\right)=0$. Each bidder's values are minimum and maximum of two independent draws from a uniform distribution on the interval $[0, \bar{v}]$.

${ }^{12}$ The first-order condition implies that $2 b_{2}\left(v_{2}-b_{2}\right)=2 \bar{v} v_{2}-v_{2}^{2}-b_{2}^{2}$. It cannot be satisfied for any $b_{2} \in\left[R, v_{2}\right] \subseteq(0, \bar{v})$. This often occurs in this multi-unit auction by EngelbrechtWiggans and Kahn (1998a, Section 4 and Example 1).
} 
If the seller allocates all $k$ units to those who value them the most, then the total welfare that could be (potentially) distributed among all bidders is

$$
P W=\sum_{j=1}^{k} w_{j}
$$

where $w_{j}$ is the $j$ th highest value of all bidders' initial and subsequent values.

But in an auction the seller allocates units according to submitted bids. As the bidders do not necessarily reveal the true value in their subsequent bids, the auction welfare that is distributed among all bidders is

$$
A W=\sum_{j=1}^{\min (k, K)} W_{j}
$$

where $K$ denotes the number of accepted bids and $W_{j}$ is the value corresponding to the $j$ th highest bid of all bidder's initial and subsequent bids. In other words, the values $W_{1}, \ldots, W_{\min (k, K)}$ are the winning values in the auction.

I introduce the following measure of expected efficiency (cf. with Palfrey (1983), and Alsemgeest, Noussair and Olson (1998)) defined as ${ }^{13}$

$$
W(R)=\frac{E(A W)}{E(P W)}=\frac{E\left(\sum_{j=1}^{\min (k, K)} W_{j}\right)}{E\left(\sum_{j=1}^{k} w_{j}\right)} .
$$

The expected efficiency loss in the auction I define as

$$
\operatorname{Loss}(R)=E(P W)-E(A W)=E\left(\sum_{j=1}^{k} w_{j}\right)-E\left(\sum_{j=1}^{\min (k, K)} W_{j}\right) .
$$

$A W$ is a function of bidder's strategies, and therefore efficiency and loss also depend on the reservation price $R$.

\footnotetext{
${ }^{13} \mathrm{An}$ alternative measure of efficiency is $\overline{\operatorname{Eff}}(R)=E\left(\sum_{j=1}^{\min (k, K)} W_{j} / \sum_{j=1}^{k} w_{j}\right)$. Note that Theorem 4, the final one, is valid even using this measure (cf. Swinkels (1999)).
} 
Lemma 1. The seller who maximizes the mean value of all bidder utility (3.8), maximizes the expected auction efficiency or minimizes expected loss (3.10), chooses the same optimal reservation price $R$.

$$
\arg \max _{0 \leq R \leq \bar{v}} E(A W)=\arg \max _{0 \leq R \leq \bar{v}} W(R)=\arg \min _{0 \leq R \leq \bar{v}} \operatorname{Loss}(R) .
$$

Let us assume a seller is somehow able to transfer the auction revenue among bidders in a lump-sum way. Intuition would explain that the seller is the government selling state property (e.g., radio frequency licenses or T-bills). The government's main goal should be not only to maximize the revenue or minimize interest rate costs, but also to maximize the bidders' welfare. The ultimate criterion for the seller could place some weight $t$ on revenue and weight $1-t$ on bidders' welfare $(0 \leq<t \leq 1)$. Then, the society objective function is

$$
t \operatorname{Rev}(R)+(1-t) E(A W)=t \operatorname{Rev}(R)+(1-t)(E(P W)-\operatorname{Loss}(R)) .
$$

I will use the term to optimize efficiency loss or efficiency to mean any of the equivalent measures in lemma 1 and the term welfare to mean (3.12).

\section{THE EFFECT OF RESERVATION PRICE ON EFFICIENCY}

In this section I disentangle two sources of efficiency loss. Then I show that the effect of a reservation price increase on each source of inefficiency is opposite and setting the reservation price above zero is typically optimal that is the main point of the paper. I specify conditions when 0 is not an efficient optimal reservation price and the seller who sets a positive reservation price decreases expected efficiency loss when allocating the units to the bidders.

First note that the single-unit symmetric first-price auction is efficient if the seller sets a zero reservation price. In a symmetric equilibrium, all bidders use symmetric strategies, and if the reservation price is zero, there is no efficiency loss in the final allocation. The multi-unit Vickrey auction is efficient if the 
seller sets a zero reservation price. In this auction all bidders use the same (true-value revealing) strategy on all private values. If the seller sets a positive reservation price in either of these two auctions, then the bidders with values below the reservation price do not participate in the auction. This introduces efficiency loss because the seller's value of the units he does not sell in the auction is zero. ${ }^{14}$

In the multi-unit uniform-price auction with zero reservation price, the auction allocation is not efficient (see Engelbrecht-Wiggans and Kahn (1998a), Noussair (1995)). One explanation is that a necessary condition for an efficient auction method (Krishna (2002, Proposition 13.3.) is violated. Namely, bidders do not apply the same mapping from value to bid (e.g., bidders do not bid the true value both on the initial and subsequent value). Due to the difference in shading across initial and subsequent units, the seller who uses the bids to distribute units is not able to allocate them efficiently.

In section $1 \mathrm{I}$ outlined that shading in equilibrium strategies (3.4) motivates a bidder with high subsequent value to submit a bid below an opponent bidder's initial bid of low initial value (see Figure 1, and Figure 2 below). If the seller specifies a reservation price, some of the bidders do not submit bids above the reservation price, but the others submit higher bids and shade less of their true values. This means that bids on subsequent units more precisely reveal the true values, the initial and subsequent strategy of each bidder become more symmetric and the seller allocates units efficiently more often (see Figure 1). In other words, some misallocations caused by the shading difference in initial and subsequent strategies can be eliminated by properly setting the reservation price.

\footnotetext{
${ }^{14}$ Note that the qualitative result is valid even if the seller assigns positive value to retained units (Krishna (2002)).
} 


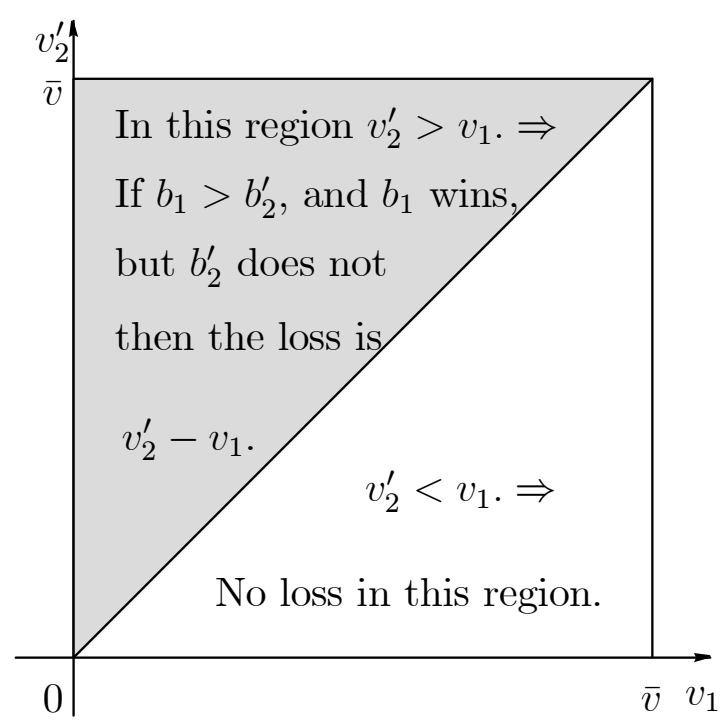

Figure 2: Efficiency loss MLoss with zero reservation price.

From the seller's point of view, different cases can be identified when the efficiency loss occurs according to the number of bids submitted. I distinguish between misallocation effect and supply restriction effect similarly as in Jehiel and Moldovanu (2001a). In each case the effect of the reservation price on efficiency is different.

- Loss due to misallocated units that occurs when more than $k$ submitted bids are above $R$ or at $R$. Due to the difference in shading across initial and subsequent values, the highest submitted bids do not necessarily correspond to the highest values and therefore units are not allocated to the bidders with the highest values, MLoss.

- Loss due to unallocated units that occurs when less than $k$ submitted bids are above $R$ or at $R, U L o s s$.

Note that in the remaining case when exactly $k$ submitted bids are above $R$ 
or at $R$, no loss occurs. The reason is that in equilibrium (3.4) bidders submit bids above $R$ or at $R$ if and only if their values are above $R$ or at $R$. But then the submitted bids correspond to the $k$ highest values and the seller allocates the units to the bidders with highest values that are efficient. ${ }^{15}$

Obviously an analog of $U$ Loss is, but MLoss is not, present in a standard single-unit auction symmetric equilibrium. In the symmetric single-unit auction with the reservation price, the loss occurs only if no bidder submits a bid above $R$ or at $R$, and the seller has no value for the unit when it is not sold in the auction. In the uniform-price auction, ULoss occurs if not all $k$ units are sold in the auction because less than $k$ bids are submitted above a too high reservation price $R$. Given the shape of equilibrium strategies (3.4), this means that if any value $v$ (initial or subsequent) below the reservation price is one of the $k$ highest values, then ULoss occurs. Consider one bidder with values $v_{1}, v_{2}$, then his values contribute to ULoss with the term

$$
\begin{aligned}
& E\left(v_{1} \mid R>v_{1} \& \text { at most } k-1 \text { opponents' values are above } v_{1}\right)+ \\
& E\left(v_{2} \mid R>v_{2} \& \text { at most } k-2 \text { opponents' values are above } v_{2}\right)
\end{aligned}
$$

The expected value of this kind of loss, denoted as $U$ Loss $(R)$, is characterized by the following theorem (see proof in the Appendix).

Theorem 2. The expected value of ULoss is

$$
\operatorname{ULoss}(R)=n \cdot\left(\int_{0}^{R} v_{1} H_{k-1}\left(v_{1}\right) d G_{1}\left(v_{1}\right)+\int_{0}^{R} v_{2} H_{k-2}\left(v_{2}\right) d G_{2}\left(v_{2}\right)\right),
$$

where $H_{l}(x)$ is the probability distribution function of the event when at most $l$ out of the $2 \cdot(n-1)$ opponent values are above $x$.

$$
H_{l}(x)=P(\text { at most } l \text { out of } 2 n-2 \text { opponent values }>x)
$$

\footnotetext{
${ }^{15}$ Recall also that no ties occur in equilibrium with positive probability and that is why we need not analyze the case of ties (see Bresky (2008b) or Engelbrecht-Wiggans and Kahn $(1998 \mathrm{a}))$.
} 
$\left.=\sum_{\substack{0 \leq i_{2}+i_{1} \leq l \\ i_{1}, i_{2} \geq 0}} \frac{(n-1) !}{i_{2} ! i_{1} !\left(n-1-i_{2}-i_{1}\right) !}\left(1-G_{2}(x)\right)\right)^{i_{2}}\left(G_{2}(x)-G_{1}(x)\right)^{i_{1}} G_{1}^{n-1-i_{2}-i_{1}}(x)$.

$U \operatorname{Loss}(R)$ is increasing in $R$, and $U \operatorname{Loss}(0)=0$, and if $G_{1}(\cdot)$ and $G_{2}(\cdot)$ are continuous, then $U$ Loss $(R)$ is continuous in $R$.

The MLoss is illustrated in Figure 2. Let me consider two bidders and their opponents when $2 \leq k \leq 2 \cdot(n-1)$. I denote the initial value of the first bidder as $v_{1}$ and the subsequent value of the second bidder as $v_{2}^{\prime}$ and let $b_{1}$ be the bid of the first bidder on $v_{1}$ and $b_{2}^{\prime}$ be the bid of the second bidder on $v_{2}^{\prime}$. Efficiency loss MLoss occurs if it is defined in such a way that the two values $v_{2}^{\prime}, v_{1}$ of the two bidders contribute to it if $v_{1}$ is one of the highest values but $v_{2}^{\prime}$ is not and $b_{2}^{\prime}$ wins a unit but $b_{1}$ does not. Given that bidders use equilibrium strategies (3.4), let me consider that $v_{2}^{\prime}$ above $R$ or at $R$ and $v_{1}$ such that $v_{2}^{\prime}>v_{1}>b_{2}^{\prime}$, then I argue in the appendix that the difference $v_{2}^{\prime}-v_{1}$ contributes to MLoss if and only if at least $k-2$ opponent values are above $v_{2}^{\prime}$, and at most $k-2$ opponent values are above $v_{1}$. ${ }^{16}$ There are $n \cdot(n-1)$ of such combinations of the two bidders. Therefore the expected value of this loss that I denote as $M \operatorname{Loss}(R)$ is characterized by the following theorem.

\footnotetext{
${ }^{16}$ One can check that if at least $k-2$ opponent values are above $v_{2}^{\prime}$, and at most $k-2$ opponent values are above $v_{1}$, then $b_{1}$ must win a unit but $b_{2}^{\prime}$ does not.
} 


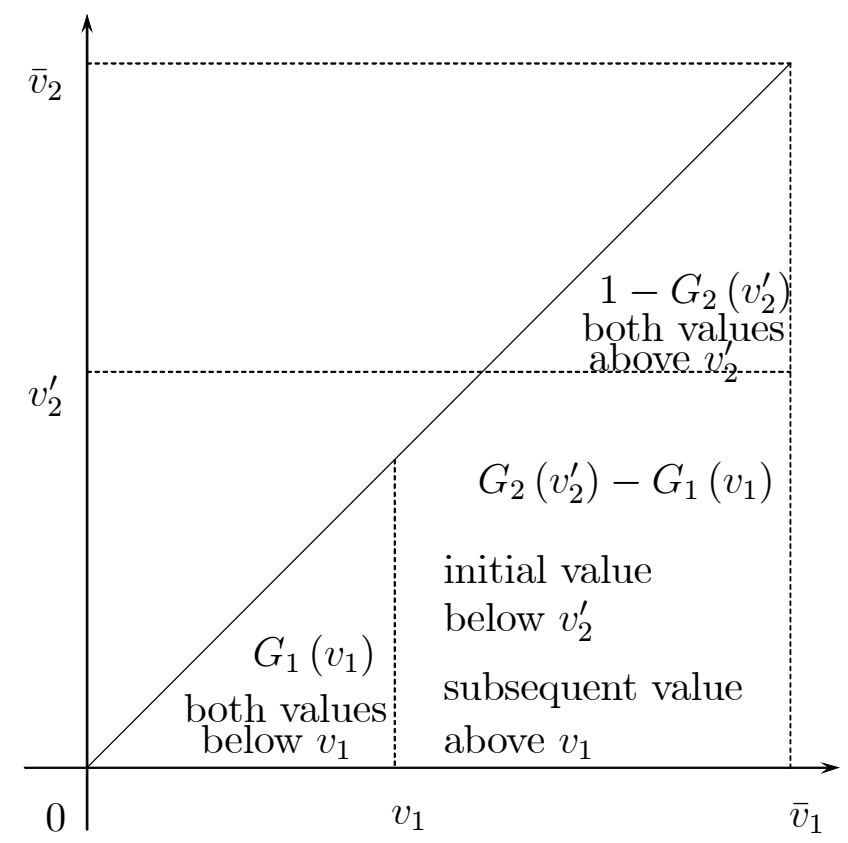

Figure 3 : Marginal probability distribution terms.

Theorem 3. The formula for MLoss $(R)$ is

$$
\begin{gathered}
\operatorname{MLoss}(R)=n \cdot(n-1) \cdot \int_{R}^{\bar{v}_{2}} \int_{b_{2}\left(v_{2}^{\prime}, R\right)}^{v_{2}^{\prime}}\left(v_{2}^{\prime}-v_{1}\right) \Omega\left(v_{2}^{\prime}, v_{1}\right) d G_{1}\left(v_{1}\right) d G_{2}\left(v_{2}^{\prime}\right), \\
\text { where } \Omega\left(v_{2}^{\prime}, v_{1}\right)=\sum_{\substack{0 \leq j \leq\left\lfloor\frac{k}{2}\right\rfloor-1 \\
0 \leq n-k+j}} \frac{(n-2) !}{j !(k-2 j-2) !(n-k+j) !} \Omega_{j}\left(v_{2}^{\prime}, v_{1}\right), \text { and } \\
\Omega_{j}\left(v_{2}^{\prime}, v_{1}\right)=\left(1-G_{2}\left(v_{2}^{\prime}\right)\right)^{j}\left(G_{2}\left(v_{2}^{\prime}\right)-G_{1}\left(v_{1}\right)\right)^{k-2 j-2} G_{1}^{n-k+j}\left(v_{1}\right)
\end{gathered}
$$

For $k<2 n-1, \operatorname{MLoss}(R)$ is a decreasing function of $R$ if the equilibrium strategy $b_{2}\left(v_{2}^{\prime}, R\right)$ is increasing in $R$ for any $v_{2}^{\prime} \in\left(R, \bar{v}_{2}\right]$. Moreover, if the equilibrium strategy is continuous in $R$, and since $G_{1}(\cdot)$ and $G_{2}(\cdot)$ are continuous, then $M$ Loss $(R)$ is continuous in $R$. 
The terms of $\Omega_{j}\left(v_{2}^{\prime}, v_{1}\right)$ are illustrated in Figure 3 and explained in the appendix. Let me illustrate the effect of reservation price change on the MLoss, ULoss, Loss and welfare measure (3.12) in the following

Example 2. Let me consider the same settings as in example 1 with two units for sale and two bidders with equilibrium strategies (3.5). In the case that there are exactly two bids submitted above or at the reservation price, they must correspond to the only two values above or at the reservation price in equilibrium. Otherwise some bidder with value above the reservation price would be better off bidding above or at the reservation price, or the bidder who has value below the reservation price would be better off bidding below the reservation price. In other words, the units are allocated to those who value them the most.

Now consider the case that more than two bids, hence more than two values, are above or at the reservation price. Let $v_{1}$ and $v_{2}$ be the values of the first bidder, and $v_{1}^{\prime}$ and $v_{2}^{\prime}$ be the values of the second bidder. If $v_{1}^{\prime}>v_{2}^{\prime}>v_{1}>$ $\max \left(R, v_{2}\right)$, or $v_{1}>v_{2}>v_{1}^{\prime}>\max \left(R, v_{2}^{\prime}\right)$, then each bidder wins one unit, but the final allocation is not efficient. Efficiency loss with zero reservation price, when $v_{2}^{\prime}>v_{1}$, is represented by the above diagonal triangle on Figure 2. Substituting the marginal probability distributions of initial and subsequent values $G_{1}\left(v_{1}\right)=v_{1}^{2}$, and $G_{2}\left(v_{2}\right)=v_{2} \cdot\left(2-v_{2}\right)$ to equation (4.1) the expected value of efficiency loss is

$$
\operatorname{MLoss}(R)=\frac{\bar{v}}{15}-\frac{2}{3} \frac{R^{2}}{\bar{v}}+\frac{4}{3} \frac{R^{3}}{\bar{v}^{2}}-\frac{R^{4}}{\bar{v}^{3}}+\frac{4}{15} \frac{R^{5}}{\bar{v}^{4}} .
$$

Note also that if the seller would have set the reservation price in such a way that $v_{1}^{\prime}>v_{2}^{\prime}>R>\max \left(v_{1}, v_{2}\right)$, or $v_{1}>v_{2}>R>\max \left(v_{1}^{\prime}, v_{2}^{\prime}\right)$, then only two bids are submitted above or at the reservation price and it is efficient as discussed before. Moreover, the seller raises higher revenue $2 \cdot R$. This illustrates how the higher reservation price may improve both efficiency and seller's revenue. 
Now let me consider the case when less than two submitted bids, hence less than two values, are above or at the reservation price and not all units are sold in the auction. Then $v_{1}$ of one bidder contributes to ULoss if and only if $\min \left(v_{1}^{\prime}, R\right)>v_{1}>v_{2}^{\prime}$ and $v_{2}$ of the bidder contributes to ULoss if and only if $R>v_{2}>v_{1}^{\prime}$. By (4.3) the expected loss is $U$ Loss $(R)=3 R^{4} / \bar{v}^{3}-12 R^{5} / 5 \bar{v}^{4}$.

The expected value of total efficiency loss with the reservation price is just a summation of MLoss and ULoss because they represent mutually disjoint cases

$$
\operatorname{Loss}(R)=\operatorname{MLoss}(R)+U \operatorname{Loss}(R)=\frac{\bar{v}}{15}-\frac{2}{3} \frac{R^{2}}{\bar{v}}+\frac{4}{3} \frac{R^{3}}{\bar{v}^{2}}+2 \frac{R^{4}}{\bar{v}^{3}}-\frac{32}{5} \frac{R^{5}}{\bar{v}^{4}} .
$$

The seller who minimizes this expression sets the reservation price at $R_{E}=$ $0.250 \bar{v}$. For the sake of brevity I will just provide the formula for the seller's revenue: ${ }^{17}$

$$
\operatorname{Rev}(R)=R \cdot\left(2 \cdot\left(L^{2,0}+2 \cdot L^{1,1}+2 \cdot L^{0,2}+2 \cdot L^{1,0}\right)+2 \cdot L^{0,1}+0 \cdot L^{0,0}\right) .
$$

The maximum revenue is achieved at $R_{R}=0.581 \bar{v}$.

There exists some ex ante optimal reservation price maximizing the seller's ex ante revenue and a different ex ante optimal reservation price maximizing ex ante efficiency. But these two optimum reservation prices do not coincide (typically $R_{E}<R_{R}$ ). The seller sets a trade-off between these two criteria in equilibrium. These two criteria define boundaries for the optimal reservation price. The ultimate criterion for the seller could be (3.12), where $t$ represents the trade-off between revenue and efficiency loss. Intuitively one can imagine that a unit gain in revenue can be distributed among bidders in such a way that their welfare increases by $\frac{t}{1-t}$ units. For $t=\frac{1}{2}$, the optimal reservation price is $R_{W}=0.496$.

\footnotetext{
${ }^{17}$ where $L^{i_{2} i_{1}}=\frac{n !}{i_{2} ! i_{1} !\left(n-i_{2}-i_{1}\right) ! \bar{v}^{2 n}}(\bar{v}-R)^{2 i_{2}+i_{1}} \cdot R^{2 n-2 i_{2}-i_{1}}$ is the probability that exactly $i_{1}\left(i_{1}=0,1,2\right)$ bidders have their initial values above $R$ and subsequent values below $R$, exactly $i_{2}\left(i_{2}=0, \cdots, n-i_{1}\right)$ bidders have both values above $R$, and other $n-i_{1}-i_{2}$ bidders have both values below $R$.
} 
It is intuitive that a positive reservation price usually increases a bidder's subsequent strategy and also the seller's revenue, but I will not investigate the effect on revenue in detail because it exceeds the scope of this paper. Let me now investigate the effect of $R$ on $M$ Loss $(R)$ and $U$ Loss $(R)$ if more than one submitted bid cannot win $(k=2, \cdots, 2 n-2)$. Note that if $M$ Loss occurs, then all $k$ units are sold in the auction but if $U$ Loss occurs, less than $k$ units are sold. Therefore they do not occur simultaneously and total Loss $(R)$ is just the sum of $U$ Loss $(R)$ and $M$ Loss $(R)$. Example 2 illustrates that a seller who optimizes Loss $(R)$ or any equivalent efficiency measure faces a trade off between $M$ Loss and ULoss. The following theorem (proved in the Appendix) shows that the reservation price that minimizes the total expected loss is typically positive.

Theorem 4. Consider a symmetric equilibrium strategy increasing in $R$ for any $R$ close enough to 0 when $k=2, \cdots, 2 n-2$. Assume that for some $\bar{v}_{0}>0$ and every $v_{2} \in\left[0, \bar{v}_{0}\right]$, the bidder bids 0 if the reservation price is 0 . Then $M$ Loss $(0)+U \operatorname{Loss}(0)>M$ Loss $(R)+U$ Loss $(R)$. Moreover assume that for $R$ slightly above 0 , the strategy is continuous in $R$, and $g_{1}(\cdot)$ and $g_{2}(\cdot)$ exists and satisfy the following condition:

$$
\lim _{v \rightarrow 0^{+}} \frac{v g_{2}(v)\left(G_{2}(v)-G_{1}(v)\right)^{i} G_{1}^{k-1-i}(v)}{g_{1}(v)}=0 \text { for all } i=0, \cdots, k-2,
$$

then $M$ Loss $(R)+U \operatorname{Loss}(R)$ is continuous and decreasing in $R$.

The theorem above imposes assumptions on the distribution of values and the shape of equilibrium strategy. The condition (4.4) is not too restrictive and can be relaxed in some cases. If the initial and subsequent values are distributed as the minimum and maximum of some underlying distribution, then condition (4.4) is satisfied for any distribution. ${ }^{18}$ Moreover, the other

\footnotetext{
${ }^{18}$ Let $v_{1}=\min \left(u_{1}, u_{2}\right)$ and $v_{2}=\max \left(u_{1}, u_{2}\right)$ where $u_{1}$ and $u_{2}$ have underlying probability distribution function $H(\cdot)$. Then $G_{1}(v)=H^{2}(v)$ and $G_{2}(v)=2 H(v)-H^{2}(v)$, and the limit term in condition $(4.4)$ is $\frac{2 v h(v)(2 H(v)(1-H(v)))^{i+1} H^{2(k-1-i)}(v)}{2 H(v) h(v)}=$ $=2^{i} v(1-H(v))^{i+1} H^{2 k-3-i}(v)$ which is 0 in the limit for any $H(v)$.
} 
conditions on the shape of the equilibrium strategy can be relaxed in the sense that bidders need not bid 0 for values $v_{2} \in\left[0, \bar{v}_{0}\right]$ when the reservation price is 0 . In many cases it seems to be sufficient if the derivative $\frac{\partial b_{2}(0,0)}{v_{2}}$ is not large. That implies less restrictive conditions on the distribution of bidder values and allows us to apply theorem 4 if the number of bidders is less than the number of units for sale when Corollary 5 below is not applicable. ${ }^{19}$ In summary, a positive reservation price decreases efficiency loss in the uniform-price auction in many cases.

In Engelbrecht-Wiggans and Kahn (1998a), it is shown that for most distributions including these with bounded $g_{1}(\cdot)$ on the neighborhood of 0 (see condition $\mathrm{B}$ in the Appendix), it is typical to bid 0 for low subsequent values $v_{2} \in\left[0, \bar{v}_{0}\right]$ in equilibrium if the seller sets a 0 reservation price and there are at least as many bidders as units for sale (see also Menezes and Monteiro (2005, Theorem 24)). The assumption that the reservation price increases the strategy is intuitive, and Bresky (2008b) shows that it is valid for continuous equilibrium strategies (see sufficient condition $\mathrm{C}$ in the Appendix this paper). I summarize it in the following corollary.

Corollary 5. If $g_{1}(\cdot)$ and $g_{2}(\cdot)$ exists, and the distribution of values satisfies conditions $A, B, C$ and (4.4), and $n \geq k \geq 3$, then the seller who sets a positive reservation price improves the expected efficiency of the final allocation.

An example when the density function satisfies all conditions of the corol-

\footnotetext{
${ }^{19}$ If $\alpha$ is $\limsup \sup _{R_{0} \rightarrow 0^{+}} \frac{\partial b_{2}}{\partial R}\left(R_{0}, R_{0}\right)$ and $k=3$, a sufficient condition to guarantee that Loss is decreasing for $R$ slightly above 0 is $\lim _{R \rightarrow 0^{+}} \frac{G_{1}(R)}{G_{2}\left(\frac{R}{\alpha}\right)-G_{2}(R)}<\infty$ and $\lim _{R \rightarrow 0^{+}} \frac{G_{2}(R)-G_{1}(R)}{G_{2}\left(\frac{R}{\alpha}\right)-G_{2}(R)}<\infty$. By L'Hopital's rule this sufficient condition is valid for any $G\left(v_{1}, v_{2}\right)$ if $\alpha<1$ including $n=2$. In other word, increse of $R$ improves efficiency even pooling of bids at 0 defined in Engelbrecht-Wiggans and Kahn (1998a) is not present.
} 
lary is

$$
g=\left\{\begin{array}{c}
\frac{2 v_{2}}{v_{1}^{2}} \text { for } 0 \leq v_{2} \leq v_{1} \leq \frac{1}{2} \\
8 v_{2} \text { for } 0 \leq v_{2} \leq \frac{1}{2}, \frac{1}{2} \leq v_{1} \leq 1 \\
0 \text { otherwise }
\end{array} \Rightarrow \begin{array}{l}
G_{1}\left(b_{2}\right)=b_{2} \text { for } b_{2} \in[0,1] \\
G_{2}\left(v_{2}\right)=2 v_{2} \text { for } v_{2} \in\left[0, \frac{1}{2}\right] .
\end{array}\right.
$$

Since there are no ties in equilibrium (see Engelbrecht-Wiggans and Kahn (1998a) for details), the bidder's payoff is continuous both in his strategy and his opponent's strategy. Therefore, the correspondence that assigns a set of all symmetric equilibrium strategies to any given $R$ is upper hemi-continuous in $R$. Hence, an efficient optimal reservation price exists and it is often positive according to Theorem 4 .

Finally I show that if just one submitted bid cannot win $(k=2 n-1)$, then the efficient optimal reservation price is 0 .

Theorem 6. If the number of units for sale is $2 \cdot n-1=k \geq 3$, then the reservation price maximizing efficiency $R_{E}$ is 0 .

In this auction exactly one bid does not win a unit but determines the auction price. The strategic considerations in this game are in some sense dual to a single-unit second-price auction where exactly one bid wins a unit but does not determine the auction price (see Engelbrecht-Wiggans and Kahn (2002)).

\section{CONCLUSION}

Along with other recent work, this the paper illustrates that auctions in which the individuals can purchase more than one unit and the seller sets the reservation price differ in striking ways from auctions studied before. This paper shows the significance of reservation price in a multi-unit auction with independent private-value bidders, not only for revenue-gaining, but also for efficiency or social welfare reasons. In a typical case, the outcome of the multiunit auction is not efficient. The reason for this is that bidders, although 
symmetric, use different strategies on the initial and subsequent unit they demand. This difference in strategies distorts efficiency in many cases (see Krishna (2002)). A similar distortion is well-known in an English single-unit auction with asymmetric bidders or in the case when the seller favors one group of bidders over the rest of the bidders (see McAfee and McMillan (1987)). But in a multi-unit auction the difference in strategies occurs even though the bidders are symmetric, risk-neutral, independent private-valued, and payment is a function of the bids alone (cf. with assumptions $A_{1}-A_{4}$ in McAfee and McMillan (1987)).

One of the principal goals of the literature survey in Zheng (2008) is a trade off between efficiency and revenue in auctions. In this paper I use a differential equation approach to derive a comparative statics result on the effect of the reservation price on efficiency and revenue in the uniform-price multi-unit auction. I disentangle two sources of efficiency loss because the reservation price has two effects: 1) it excludes bidders with values below the reservation price from the auction; and 2) it motivates the bidders to bid closer to their true values above the reservation price. The former effect decreases revenue and introduces efficiency loss if not enough bidder values, and hence bids, are above the reservation price. The latter effect improves both the efficiency and the revenue if enough values, and hence the bids, are submitted above the reservation price. For low reservation prices, the latter case occurs more often and, therefore, an increase of the reservation price improves the efficiency. This is in contrast to the single-unit first- and second-price auction models in McAfee and McMillan (1987) with symmetric bidders. Palfrey (1983) shows that the seller who sells units in bundles may increase revenue at the expense of efficiency. In contrast, I show that a positive reservation price not far from zero increases both revenue and efficiency in the uniform-price auction.

The influence of the reservation price depends on the level of shading or 
demand reduction on each unit. The shading varies for each auction format. For the uniform-price auction, the effect of the reservation price on efficiency is opposite than for the Vickrey auction, when the reservation price is not far from 0 . A question for future research is what effect prevails for other auction formats (e.g., pay-your-bid) that has been only partially studied in the multiunit auction literature (Swinkels (1999), and Lebrun and Tremblay(2003)). It seems that proper reservation price setting is an important mechanism design tool to set up an optimal multi-unit auction when the number of bidders is not large.

The efficient optimal reservation price depends on the number of bidders. The marginal increase in efficiency is not too great if there are many bidders in the auction, but it determines the kind of lower bound of the optimal reservation price which maximizes both revenue and efficiency. Therefore, the government as a seller who cares about both revenue and efficiency should never set the reservation price below this lower bound.

Although I used an independent-private value assumption, this model is applicable to other real uniform-price auctions because they are typically regarded as a mixture of independent private-value and common-value paradigms. In this case there is no general auction mechanism to achieve ex post efficiency. One application is to the auctions of licenses for the radio-frequency spectrum (PCS) by the Federal Communication Commission (certainly there are a lot of institutional details that make the analysis more complicated, see Krishna and Rosenthal (1996)). Another important application is the uniformprice auction of T-bill securities (T-bills) if the common-value assumption seems not to be appropriate. Hortacsu and Kastl (2008) could not reject the hypotheses of the private value component in 3-months T-bills. Moreover, T-bill auctions can be treated as a partially independent value auction if the secondary market is far enough from perfect liquidity, which is typical for 
emerging markets (e.g., the T-bill market in the Czech Republic and other CEEC).

It seems, at least intuitively, that the reservation price increases efficiency even if we enrich the model by a more complicated demand curve that has uncertainty in every demanded unit or assuming interdependencies among the bidder values (or signals). This intuition supports the result of EngelbrechtWiggans and Kahn (1998a), who formed the transformation of a class of 3 unit demand models into 2 unit demand models. Finally, although comparisons between the uniform-price and pay-your-bid auctions are difficult (cf. Katzman (1999)) it seems that the uniform-price auction requires more information gathering and strategic considerations from the seller to design the auction because the auction outcome is more sensitive to an optimal reservation price than the pay-your-bid auction.

\section{APPENDIX}

Proof of lemma 1. The optimization $E(A W)$ differs from criterion (3.9) only by the multiplicative term $\frac{1}{E(P W)}$, which is independent of $R$. The optimization $E(A W)$ differs from criterion (3.10) only by a linear transformation with the additive term $E(P W)$ and the multiplicative term -1 , which is independent of $R$.

Q.E.D.

Proof of theorem 2. The formula (4.2) is fairly intuitive. The term 1 $G_{2}(x)$ is the probability that a bidder has both values above $x$. The term $G_{2}(x)-G_{1}(x)$ is the probability that a bidder has an initial value above $x$ and a subsequent value below $x$, and the term $G_{1}(x)$ is the probability that a bidder has both values below $x$. Each term in the summation (4.2) is the probability that exactly $2 i_{2}+i_{1}$ values of $n-1$ bidders are above $x$. This can be arranged by $\frac{(n-1) !}{i_{2} ! i_{1} !\left(n-1-i_{2}-i_{1}\right) !}$ combinations when exactly $i_{1}$ out of 
$n-1$ bidders have their initial values above $x$ and subsequent values below $x$, exactly $i_{2}$ out of $n-1$ bidders have both values above $x$, and other bidders out of $n-1$ bidders have both values below $x$. The $U$ Loss $(R)$ in (4.1) is $n$ times the expected contribution of a single bidder's initial and subsequent values $v_{j}(j=1,2)$ that are below the reservation price and above the $k-j$ th highest opponent value. Finally note that standard properties of the primitive function imply continuity and increasingness in $R$ because $R$ monotonically influences only the integration range of nonnegative function.

A simple hint for deriving $H_{l}(x)$ is to realize that the terms in the summation (4.2) are from $1=\left(\left(1-G_{2}(x)\right)+\left(G_{2}(x)-G_{1}(x)\right)+G_{1}(x)\right)^{n-1}=$ $\left.\sum_{2 n-2 \geq 2 i_{2}+i_{1} \geq 0} \frac{(n-1) !}{i_{1} ! i_{1} !\left(n-1-i_{2}-i_{1}\right) !}\left(1-G_{2}(x)\right)\right)^{i_{2}}\left(G_{2}(x)-G_{1}(x)\right)^{i_{1}} G_{1}^{n-1-i_{2}-i_{1}}(x)$. It is similar to deriving the probability distribution function of order statistics from $1=((1-F(x))+F(x))^{n-1}=\sum_{n-1 \geq j \geq 0} \frac{(n-1) !}{j !(n-1-j) !}(1-F(x))^{j} F^{n-1-j}(x)$ (cf. Wikipedia (2009)).

Proof of theorem 3. Efficiency loss is defined in such a way that the two values $v_{2}^{\prime}, v_{1}$ of the two bidders contribute to it if $v_{1}$ is one of the highest values but $v_{2}^{\prime}$ is not and $b_{2}^{\prime}$ wins a unit but $b_{1}$ does not. Consider any pair of two bidders. Let me denote as $v_{1}$ the initial value of the first bidder and $v_{2}^{\prime}$ as the subsequent value of the second bidder. Since there are $n \cdot(n-1)$ of such different pairs, the integral in formula (4.3) is multiplied by $n \cdot(n-1)$. Next, all opponents of the two bidders I denote as $O$. Given the equilibrium strategies (3.4), the difference $v_{2}^{\prime}-v_{1}$ contributes to MLoss if and only if:

1. $v_{2}^{\prime}$ is above the reservation price, and $v_{2}^{\prime}>v_{1}=b_{1}\left(v_{1}, R\right)>b_{2}\left(v_{2}^{\prime}, R\right)$; and

2. for some $j=0, \cdots,\lfloor k / 2\rfloor-1$ the value realizations of the opponents in $O$ are as follows: $j$ subsequent's opponent values are above $v_{2}^{\prime}, n-k+j$ 
initial values of another opponent's are below $v_{1}$, and $k-2 j-2$ remaining opponents' initial values are above $v_{1}$ and subsequent values are below $v_{2}^{\prime 20}$

The inequalities in point 1 above is expressed in the range of integration in formula (4.3). The probability of the realization of opponent values in point 2 above is expressed in $\Omega_{j}\left(v_{2}^{\prime}, v_{1}\right)$. There are $\frac{(n-2) !}{j !(n-k+j) !(k-2 j-2) !}$ combinations of each realizations in point 2 . Since for any $j \neq j^{\prime}$, the cases in this point above do not occur simultaneously, one can just sum up $\frac{(n-2) !}{j !(n-k+j) !(k-2 j-2) !} \Omega_{j}\left(v_{2}^{\prime}, v_{1}\right)$ into $\Omega\left(v_{2}^{\prime}, v_{1}\right)$. Next, it is easy to check that the term $\Omega\left(v_{2}^{\prime}, v_{1}\right)$ is the probability that at least $k-2$ values of opponents in $O$ are above $v_{1}$ and at most $k-2$ values of opponents in $O$ are above $v_{2}$. Therefore $v_{1}$ is one of the $k$ highest values but $v_{2}^{\prime}$ is not, and $b_{1}$ is one of the $k$ highest bids but $b_{1}$ is not. ${ }^{21}$ Finally note that the standard properties of primitive function imply continuity and increasingness in $R$ because $R$ monotonically influences only the integration range of the nonnegative function.

A simple hint how for deriving $\Omega\left(v_{2}^{\prime}, v_{1}\right)$ is to realize that the terms in the summation (4.3) can be derived when expanding $1=\left(\left(1-G_{2}\left(v_{2}^{\prime}\right)\right)+\left(G_{2}\left(v_{2}^{\prime}\right)-G_{1}\left(v_{1}\right)\right)+G_{1}\left(v_{1}\right)\right)^{n-2}$ similarly as I suggest in the proof of theorem 2 (see also Wikipedia (2009)).

Q.E.D.

\footnotetext{
${ }^{20}$ The equilibrium strategies (3.4) ensures that for any $j$ there are at least $k-2$ opponent bids and both bidder initial bids above $b_{2}\left(v_{2}^{\prime}, R\right)$ and at most $k-2$ opponent bids and the second bidder's initial bid are above $b_{1}\left(v_{1}, R\right)=v_{1}$, which implies that $b_{1}\left(v_{1}, R\right)$ wins but $b_{2}\left(v_{2}^{\prime}, R\right)$ does not.

${ }^{21}$ Note that since the initial value of both bidders, and hence bids, are above $v_{2}^{\prime}$, and also the initial (but not subsequent) bid of the second bidder are above $v_{1}$, there are at least $k$ bids above $b_{2}^{\prime}$ and at most $k-1$ bids below $b_{1}$ in total. In other words, $b_{1}$ must win a unit but $b_{2}^{\prime}$ does not.
} 
Proof of theorem 4. The fact that $b_{2}\left(v_{2}, R\right) \geq R$ for $v_{2} \geq R$ implies that $M \operatorname{Loss}(0)-M \operatorname{Loss}(R)$ is at least

$$
\int_{R}^{\bar{v}_{0}} \int_{0}^{R}\left(v_{2}-v_{1}^{\prime}\right) n(n-1) \Omega\left(v_{2}, v_{1}^{\prime}\right) d G_{1}\left(v_{1}^{\prime}\right) d G_{2}\left(v_{2}\right) .
$$

Let me rearrange the expression for the demand loss difference.

$$
U \operatorname{Loss}(0)-U \operatorname{Loss}(R)=\int_{R}^{\bar{v}_{0}} \frac{U \operatorname{Loss}(0)-U \operatorname{Loss}(R)}{G_{2}\left(\bar{v}_{0}\right)-G_{2}(R)} d G_{2}\left(v_{2}\right) .
$$

Therefore $M$ Loss $(0)+U \operatorname{Loss}(0)-M \operatorname{Loss}(R)-U \operatorname{Loss}(R)$ is at least

$$
\int_{R}^{\bar{v}_{0}} n \int_{0}^{R}\left[\left(v_{2}-v\right)(n-1) \Omega\left(v_{2}, v\right) g_{1}(v)-\frac{v H_{k-1}(v) g_{1}(v)}{G_{2}\left(\bar{v}_{0}\right)-G_{2}(R)}-\frac{v H_{k-2}(v) g_{2}(v)}{G_{2}\left(\bar{v}_{0}\right)-G_{2}(R)}\right] d v d G_{2}\left(v_{2}\right) .
$$

I show that the integrand above consisting of three additive terms is positive for any $v$ sufficiently close to 0 and any $k=2, \cdots, 2 n-2$. At first note that

$$
\lim _{v \rightarrow 0^{+}} \frac{\Omega\left(v_{2}, v\right)}{G_{1}^{n-k}(v)}=\lim _{v \rightarrow 0^{+}} \frac{\Omega_{0}\left(v_{2}, v\right)}{G_{1}^{n-k}(v)}=G_{2}^{k-2}\left(v_{2}\right)>0 \text { and } \lim _{v \rightarrow 0^{+}} \frac{v H_{k-1}(v)}{G_{1}^{n-k}(v)}=0 .
$$

Since $\lim _{R \rightarrow 0^{+}} G_{2}\left(\bar{v}_{0}\right)-G_{2}(R)>0$ and $v_{2}-v>0$, the second term in the integrand is negligible with respect to the first one for $v$ sufficiently close to 0 . Finally note that the third integrand term is negligible with respect to the first one because $\lim _{v \rightarrow 0^{+}} \frac{v H_{k-2}(v) g_{2}(v)}{G_{1}^{n-k}(v) g_{1}(v)}=0$, which is an implication of condition (4.4).

Therefore $M \operatorname{Loss}(0)+U \operatorname{Loss}(0)-M \operatorname{Loss}(R)-U \operatorname{Loss}(R)$ is positive for any $R$ sufficiently close to 0 . Moreover if the strategy is continuous in $R$, then $M$ Loss $(R)+U$ Loss $(R)$ is continuous in $R$. Therefore it must be that $M \operatorname{Loss}(R)+U \operatorname{Loss}(R)$ is decreasing in the neighborhood of 0 .

Q.E.D.

Comments to corollary 5. The conditions A, B, and C (below) on the distribution of values used in this paper are discussed in more detail in EngelbrechtWiggans and Kahn (1998a), Menezes and Monteiro (2005, Lemma 10, and 
Theorem 24) and Bresky (2008b). They are sufficient to guarantee that equilibrium strategies are "well-behaved," and if one relaxes them Theorem 4 is anyway applicable in some cases.

The conditions $\mathrm{A}$ and $\mathrm{B}$ below guarantee that in equilibrium a bidder reveals his initial value in the initial bid and the subsequent bid is an increasing function of value $v_{2}$ up to the range of $v_{2}$ from $\left[R, \bar{v}_{0}\right)$ when $k \leq n$; (see equation $(3.4))$

Condition A. The distribution of the values of one bidder is independent of the opponent value realization, and for every $v_{2}>0$, there is a number $\varepsilon>0$ such that for any valuation $v_{1} G_{2}\left(v_{2} \mid v_{1}\right)>\varepsilon$.

In other words, condition A says that for any $v_{1}$ there is some chance that $v_{2}$ is close to 0 . This condition is valid if any open subset of $\mathcal{V}$ has a positive measure.

Engelbrecht-Wiggans and Kahn (1998a) show that the next condition is sufficient for the existence of an equilibrium strategy (3.4) with $\bar{v}_{0}>0$ when the reservation price is 0 and there are at least as many bidders as units for sale.

Condition B. The marginal density $g_{1}\left(v_{1}\right)$ is bounded in some neighborhood of 0 .

Moreover, in the body of the paper I restrict the attention to auction games with continuous subsequent equilibrium strategies in $v_{2}$ which, moreover, implies that the symmetric subsequent strategy is increasing in $R$. The idea is similar to Lizzeri and Persico (2000) who study the first-price auctions with reservation price. Bresky (2008b) shows that the two subsequent equilibrium strategies cannot cross, otherwise a better response can be constructed. Then, since it is equilibrium strategy to bid $b_{2}(R, R)=R$, it must be that $b_{2}\left(v_{2}, \cdot\right)$ is increasing in $R$. The following condition is sufficient to guarantee that every symmetric equilibrium strategy is continuous in $v_{2}$ and increasing in $R$. 
Condition C. The marginal density $g_{2}(\cdot)$ is weakly increasing and $(k-1) g_{1}\left(b_{2}\right)<g_{2}\left(b_{2}\right)$.

Note that if the bidders use symmetric strategies and reveal the initial value in the bid, then $\pi\left(v, b \mid b_{-}(\cdot)\right)$ depends only on $G(\cdot, \cdot), v, b$ because the bidder defeats subsequent bids of the opponents with a value below $v_{2}$. The reason is similar to the single-unit first-price auction symmetric equilibrium in which a bidder's marginal payoff can be expressed as a function of the bidder's value, the distribution of value and bid - but no opponent strategy (see McAfee and McMillan (1987)). The parallel arguments are valid for the uniform-price auction model of this paper. To understand how is condition $\mathrm{C}$ related to continuity, note that if opponents use strategy $b_{-}(v)$ with shape (3.4) such that $b_{-2}(\cdot)$ is not continuous at $v_{2}$, then the bidder's marginal payoff at the discontinuity is nonnegative; i.e., $\partial \pi\left(v, b \mid b_{-}(\cdot)\right) \overline{\partial b_{2}} \geq 0$ for some $b_{2} \in\left(\lim _{u \rightarrow v_{2}} b_{-2}\left(v_{2}\right), \lim _{u \rightarrow v_{2}^{+}} b_{-2}\left(v_{2}\right)\right)$. Next, if $n \geq k \geq 2$, then this inequality equation expands to

$\left(v-b_{2}\right) \sum_{i_{2}=0}^{\left\lfloor\frac{k-2}{2}\right\rfloor} \frac{(n-1) ! A^{i_{2}} B^{k-2-2 i_{2}}\left(b_{2}\right) G_{1}^{n-k+i_{2}}\left(u_{1}\left(b_{2}\right)\right) g_{1}\left(b_{2}\right)}{i_{2} !\left(k-2-2 i_{2}\right) !\left(n-k+i_{2}\right) !} \geq$ $\geq \sum_{i_{2}=0}^{\left\lfloor\frac{k-1}{2}\right\rfloor} \frac{(n-1) ! A^{i_{2}}\left(b_{2}\right) B^{k-1-2 i_{2}}\left(b_{2}\right) G_{1}^{n-k+i_{2}}\left(u_{1}\left(b_{2}\right)\right)}{i_{2} !\left(k-1-2 i_{2}\right) !\left(n-k+i_{2}\right) !}$ where $u_{1}(\cdot)$, and $u_{2}(\cdot)$ are the inverse of opponent strategies $b_{-}(\cdot) ; A\left(b_{2}\right)=1-G_{2}\left(u_{2}\left(b_{2}\right)\right)$ is the probability that the two bids of an opponent are above $b_{2} ; B\left(b_{2}\right)=G_{2}\left(u_{2}\left(b_{2}\right)\right)-$ $G_{1}\left(u_{1}\left(b_{2}\right)\right)$ is the probability that an opponent submits an initial bid above and the subsequent bid below $b_{2}$; and $G_{1}\left(u_{1}\left(b_{2}\right)\right)$ is the probability that two bids of an opponent are are below $b_{2}$. Note if the bidder uses the same strategy as his opponents, then $u_{2}\left(b_{2}\right)=v_{2}$, and if the opponents bid the initial value in the initial bid, $u_{1}\left(b_{2}\right)=b_{2}$. It is independent of the opponent strategy $b_{-}(\cdot)$ (see Figure 3$)$. Then comparing the corresponding summation terms, one gets the following inequalities $\left(k-1-2 i_{2}\right) g_{1}\left(b_{2}\right) \geq \frac{G_{2}\left(v_{2}\right)-G_{1}\left(b_{2}\right)}{v_{2}-b_{2}}$. Using the mean value theorem on the right side of this inequality, one gets $\left(k-1-2 i_{2}\right) g_{1}\left(b_{2}\right) \geq \frac{G_{2}\left(b_{2}\right)-G_{1}\left(b_{2}\right)}{v_{2}-b_{2}}+g_{2}(\tilde{b})$ for some $\tilde{b} \in\left[b_{2}, v_{2}\right]$ that is incom- 
patible with condition $\mathrm{C}$. Therefore, condition $\mathrm{C}$ implies that the subsequent strategy is continuous and increasing in $R$. It is also obvious that condition $\mathrm{C}$ can be relaxed but it is difficult to find another general condition.

Proof of theorem 6 . If $k=2 \cdot n-1 \geq 3$ and $R=0$, then at most one bid does not win a unit. Since the strategy is increasing in a symmetric equilibrium, to finish the proof note that the losing bid is the subsequent bid of a bidder with the lowest value.

Q.E.D.

\section{References}

Alsemgeest, Paul, Charles Noussair, and Mark Olson (1998). "Experimental Comparisons of Auctions under Single- and Multi-Unit Demand," Economic-Inquiry 36, 87-97.

Armstrong M. (1996). "Multiproduct Nonlinear Pricing," Econometrica 64, 51-75.

Ausubel, Lawrence M. (2004). "An Efficient Ascending-Bid Auction for Multiple Objects," The American Economic Review, 94 (5),1452-1575.

Ausubel, Lawrence M., and Peter C. Cramton (1996). "Demand Reduction and Inefficiency in Multi-unit Auctions," Working Paper No. 96-07, University of Maryland- Department of Economics, College Park, MD 20742.

Back, K., and J.F.Zender (1993). "Auctions of Divisible Goods: On the Rationale for the Treasury Experiment," Review of Financial Studies 6, 733764.

Blume, Andreas, Paul Heidhues, Jonathan Lafky, Johannes Münster, and Meixia Zhang (2009): "All equilibria of the multi-unit Vickrey auction," Games and Economic Behavior, forthcomming.

Bresky, Michal (2008a). "Pure Equilibrium Strategies in Multi-unit Auctions with Private value bidders," Working Paper 376, CERGE-EI, Prague. 
Bresky, Michal (2008b). "Properties of Equilibrium strategies in multipleunit private value auctions," Working Paper 354, CERGE-EI, Prague.

Dasgupta, P. S., and D. Maskin (2000). "Efficient Auctions," Quarterly Journal of Economics, 115, 341-388.

Engelbrecht-Wiggans, Richard, and Charles M. Kahn (1998a). "Multi-unit Auctions with Uniform Prices," Economic Theory 12, 227-258.

Engelbrecht-Wiggans, Richard, and Charles M. Kahn (1998b). "Multiunit Pay-Your-Bid Auctions with Variable Awards," Games and Economic Behavior 23, 25-42.

Engelbrecht-Wiggans, Richard, and Charles M. Kahn (2002). "Multiunit Auctions in Which Almost Every Bid Wins." Southern Economic Journal, Vol. 68 (3), pp. 617-31.

Hortacsu, Ali, and Jakub Kastl (2008). "Testing for Common Values in Treasury Auctions," SIEPR Discussion Paper 07-053, Stanford University.

Jackson, Matthew, and Jeroen Swinkels (2005). "Existence of Equilibrium in Single and Double Private Value Auctions," Econometrica, 73(1), 93-139.

Jehiel, Philippe, and Benny Moldovanu (2001). "Efficient Design with Interdependent Valuations," Econometrica, 69 (5), pp. 1237-1259.

Jehiel, and Moldocvanu (2001a): "A Note of Revenue Maximization and Efficiency in Multi-Object Auctions. Economics Bulletin 3 (2), pp. 1-5.

Krishna, Vijay (2002). Auction Theory, Academic Press.

Krishna, Vijay, and Robert W. Rosenthal (1996). "Simultaneous Auctions with Synergies," Games and Economic Behavior 17, pages 1-31.

Katzman, Brett (1999). "A Two Stage Sequential Auction with Multi-unit Demands," Journal of Economic Theory 86 , 77-99.

Klemperer, Paul (2000). "Auction Theory: A Guide to the Literature," in The Economic Theory of Auctions (P. Klemperer, eds.), Edward Elgar. 
Lebrun, Bernard, and Maria Tremblay (2003)). "Multiunit Pay-Your-Bid Auction With One-Dimensional," International Economic Review 44, 3.

Levin Dan (2004). "The Competitiveness of Joint Bidding in Multi-Unit Uniform-Price Auctions," The RAND Journal of Economics, Vol. 35, 2, pp. 373-385.

Lizzeri, Alessandro, and Nicola Persico (2000): "Uniqueness and Existence of Equilibrium in Auctions with a Reserve Price," Games and Economic Behavior 30, pp. 83-114.

McAdams, David (2006). "Monotone Equilibrium in Multi-Unit Auctions," Review of Economic Studies, 73, 1039-1056.

McAfee, Preston R., and John McMillan (1987). "Auctions and Bidding," Journal of Economic Literature 25, 699-738.

Menezes, Flavio, and Monteiro Paolo (2005) : An introduction to auction theory, Oxford University Press.

Morgan, John (2001) : "Efficiency in auctions: theory and practice, . Journal of International Money and Finance 20, pp. 809-838.

Noussair, Charles (1995). "Equilibria in a Multi-object Uniform Price Sealed Bid Auction with Multi-unit Demands," Economic Theory 5, 337-351.

Palfrey, Thomas (1983). "Bundling Decisions by a Multiproduct Monopolist with Incomplete Information," Econometrica 51, 463-483.

Perry, Motty and Philip Reny (1999). "On the Failure of the Linkage Principle in Multi-unit Auctions," Econometrica 67, 895-900.

Perry, Motty and Philip Reny (2005). "An Efficient Auction," Econometrica, Vol. 70, 1199-1212.

Perry, Motty and Philip Reny (2005). "An Efficient Multi-unit Ascending Auction," Review of Economic Studies, Vol. 72 (2), 567-92.

Swinkels, Jeroen (1999). "Asymptotic Efficiency for Discriminatory Private Value Auctions," Review of Economic Studies 66, 509-28. 
Swinkels, Jeroen (2001). "Efficiency of Large Auctions," Econometrica 69, $37-68$.

Vickrey William (1961). "Counterspeculation, Auctions, and Competitive Sealed Tenders," The Journal of Finance 16, 8-37.

Wikipedia (2009). http://en.wikipedia.org/wiki/Order_statistics, and http://en.wikipedia.org/wiki/Multinomial_theoremz).

Zhang, Roger (2008) : "Optimality and Efficiency in Auctions Design: A Survey," in Pareto Optimality, Game Theory And Equilibria, Springer New York, Collection in Mathematics and Statistics, pp. 437-454. 
Individual researchers, as well as the on-line and printed versions of the CERGE-EI Working Papers (including their dissemination) were supported from the following institutional grants:

- Economic Aspects of EU and EMU Entry [Ekonomické aspekty vstupu do Evropské unie a Evropské měnové unie], No. AVOZ70850503, (2005-2010);

- Economic Impact of European Integration on the Czech Republic [Ekonomické dopady evropské integrace na ČR], No. MSM0021620846, (2005-2011);

Specific research support and/or other grants the researchers/publications benefited from are acknowledged at the beginning of the Paper.

(c) Michal Břeský, 2009

All rights reserved. No part of this publication may be reproduced, stored in a retrieval system or transmitted in any form or by any means, electronic, mechanical or photocopying, recording, or otherwise without the prior permission of the publisher.

Published by

Charles University in Prague, Center for Economic Research and Graduate Education (CERGE) and

Economics Institute ASCR, v. v. i. (EI)

CERGE-El, Politických vězňŭ 7, 11121 Prague 1, tel.: +420 224005 153, Czech Republic.

Printed by CERGE-EI, Prague

Subscription: CERGE-EI homepage: http://www.cerge-ei.cz

Editors: Directors of CERGE and EI

Managing editors: Deputy Directors for Research of CERGE and EI

ISSN 1211-3298

ISBN 978-80-7343-185-3 (Univerzita Karlova. Centrum pro ekonomický výzkum

a doktorské studium)

ISBN 978-80-7344-174-6 (Národohospodářský ústav AV ČR, v. v. i.) 
CERGE-EI

P.O.BOX 882

Politických vězňů 7

11121 Praha 1

Czech Republic http://www.cerge-ei.cz 